\begin{tabular}{|c|l|}
\hline Title & $\begin{array}{l}\text { Photolytic flash-induced intercellular calcium waves using caged cal cium ionophore in cultured astrocytes from } \\
\text { newborn rats }\end{array}$ \\
\hline Author(s) & Iwabuchi, Sadahiro; Kawahara, Koichi; Makisaka, Koji; Sato, Hideomi \\
\hline Citation & $\begin{array}{l}\text { Experimental Brain Research, 146(1),103-116 } \\
\text { https://doi.org/10.1007/300221-002-1149-y }\end{array}$ \\
\hline Issue Date & 2002-09 \\
\hline Doc URL & http://hdl.handle.net/2115/5938 \\
\hline Rights & The original publication is available at www.springerlink.com \\
\hline Type & article (author version) \\
\hline File Information & EBR146..pdf \\
\hline
\end{tabular}

Instructions for use 


\title{
Photolytic flash-induced intercellular calcium waves using caged calcium ionophore in cultured astrocytes from newborn rats.
}

\author{
Sadahiro Iwabuchi, Koichi Kawahara*, Koji Makisaka, and Hideomi Sato \\ Laboratory of Biomedical Control, Research Institute for Electronic Science, Hokkaido \\ University, Sapporo 060-0812, Japan
}

*Address correspondence to:

Koichi Kawahara, PhD.

Professor of the Laboratory of Biomedical Control

Research Institute for Electronic Science

Hokkaido University

Sapporo 060-0812

JAPAN

TEL \& FAX: $+81-11-706-2893$

E-mail: kawahara@bmc.es.hokudai.ac.jp 


\begin{abstract}
Waves of elevated intracellular free calcium that propagate between neighboring astrocytes are important for the intercellular communication between astrocytes as well as between neurons and astrocytes. However, the mechanisms responsible for the initiation and propagation of astrocytic calcium waves remain unclear. In this study, intercellular calcium waves were evoked by focal photolysis of a caged calcium ionophore (DMNPE-caged $\mathrm{Br}$ A23187) in cultured astrocytes from newborn rats. The focal photolysis of the caged compound resulted in the increase of intracellular calcium in a single astrocyte, and this increase then propagated to neighboring astrocytes. We also analyzed the spatiotemporal characteristics of the intercellular calcium waves, and estimated the propagation pathways for them. The method using a caged calcium ionophore described in this study provides a new in vitro model for the analysis of intercellular calcium waves.
\end{abstract}

Key words: calcium waves, caged ionophore, photolysis, astrocytes, gap junction 


\section{Introduction}

Waves of elevated intracellular free calcium that propagate between neighboring astrocytes constitute a newly discovered form of nonsynaptic long-range signaling in the brain (Cornell-Bell et al. 1990). Although the function of such waves is not yet fully understood, glial calcium waves possibly provide an information-processing system operating in parallel with neuronal circuits within the nervous system (Guthrie et al. 1999). Previous findings have revealed that the glial calcium waves modulate the neuronal activity (Nedergaard 1994; Neuman et al. 1998), and that the neuronal activity can directly evoke glial calcium waves (Dani et al. 1992). Therefore, these findings have transformed the classical view of astrocytes as passive, structural, and supportive cells to cells that may actively participate in information processing (Parpura et al. 1994).

It has been generally accepted that intercellular calcium wave propagation involves the intracellular and extracellular calcium signaling pathways in astrocytes (Charles 1998). One mechanism of intercellular calcium waves includes the diffusion of the intracellular calcium releaser, inositol-1,4,5-trisphosphate ( $\left.\mathrm{IP}_{3}\right)$, across gap junctions (Nedergaard et al. 1994). As an extracellular calcium signaling molecule, ATP is released from stimulated astrocyte, and results in the $\mathrm{P}_{2} \mathrm{Y}_{1}$ purinoceptor-coupled calcium increase in neighboring astrocytes (Cotrina et al. 1998; Fam et al. 2000). However, the detailed mechanisms for propagation of calcium waves are not completely understood.

In most previous studies on the subject, mechanical (Fujita et al. 1998; Fam et al. 2000; Cotrina et al. 2000) or electrical (Hassinger et al. 1996; Guthrie et al. 1999) stimulation has been used to induce propagating calcium waves in cultured astrocytes. Local application of 
chemicals such as ATP was also used to evoke astrocytic calcium waves (John et al 1999). Indeed, the mechanical stimulation of single or several astrocytes with a glass pipette is a simple, but biochemically poorly defined, method of triggering intercellular calcium waves (Paemeleire and Leybaert 2000). Such a protocol may occasionally result in the destruction of stimulated astrocytes, and the resultant changes in the ionic and/or metabolic environment around intact astrocytes may initiate calcium waves. In addition, although the local application of chemicals such as ATP consistently evokes calcium waves in cultured astrocytes, it too would contribute to wave propagation (Cotrina et al. 2000). Therefore, a novel and more sophisticated protocol to initiate or trigger calcium waves in cultured astrocytes will be required to elucidate the functional roles of these waves in signal processing.

A significant tool for cell biology is the ability to uncage bio-active molecules over a rapid time scale, while observing the consequences for cellular signaling (Parpura and Haydon 1999). The development of several caged compounds including caged transmitters such as glutamate and GABA, and caged intracellular messengers such as cAMP, cGMP, and IP3, as well as other molecules such as caged nitric oxide (NO), has provided a novel analytical tool for the study of intricate intracellular signal transduction pathways (Lipp and Niggli 1998; Wiesner and Hagen 1999).

In this study, intercellular calcium waves were evoked by focal photolysis of a caged calcium ionophore in cultured astrocytes from newborn rats. The photolysis of a caged compound resulted in an increase in intracellular calcium in a single astrocyte, and the increase then propagated to neighboring astrocytes. This new in vitro model for analyzing of calcium waves is less noxious to astrocytes than mechanical stimulation. 


\section{Methods}

The animal experiments conformed to the "Principles of laboratory animal care" (NIH publication No. 85-23, revised 1996), as well as the "guide for the care and use of laboratory animals”, Hokkaido University School of Medicine.

\section{Cell culture}

Glial cells from postnatal day 1-3 rat pups were obtained using a modified version of a method reported previously (Hassinger et al. 1995). In brief, the cortical hemispheres were removed, cleaned, and dissociated using $0.01 \%$ papain (Boehringer Mannheim)-cysteine solution and mechanical trituration. Cells were placed on poly-L-lysine-coated glass coverslips at 5,000 cells/ $\mathrm{cm}^{2}$ and were maintained in 80 \% Dulbecco's Modified Eagles Medium (DMEM; Gibco BRL, Grand Island NY), 10 \% Ham's F-12 Nutrient Mixture (F-12; Gibco BRL) and $10 \%$ fetal bovine serum at $37^{\circ} \mathrm{C}$ in a humidified atmosphere of $95 \%$ air and $5 \%$ $\mathrm{CO}_{2}$. The medium was removed from coverslips and replaced with fresh culture medium $48 \mathrm{hr}$ later and twice a week thereafter. The experiments described here were performed on astrocytes maintained for 2-3 weeks in culture.

\section{Immunohistochemistry}

Astrocytes and neurons were identified by immunostaining with antibodies against glial fibrillary acidic protein (GFAP) and microtubule-associated protein 2 (MAP-2), respectively. Cultured coverslips were fixed for 30 min with $4 \%$ paraformaldehyde-PB (pH 7.4) at room 
temperature. After three more wash in PBS (0.02 M, pH 7.25), coverslips were blocked with $1 \%$ normal goat serum in dilution buffer (DB; containing PBS, $0.1 \%$ Bovine Serum Albumin, $0.05 \% \mathrm{NaN}_{3}$ ) for $30 \mathrm{~min}$ at room temperature and were then incubated overnight at $4{ }^{\circ} \mathrm{C}$ with primary antibody (monoclonal anti-GFAP, 1:400 or monoclonal anti-MAP-2, 1:1000, Sigma) in DB. Coverslips were then rinsed three times in PBS and were incubated with secondary antibody in DB for $60 \mathrm{~min}$ at room temperature. Biotinylated goat anti-mouse IgG (Vector Laboratories, Burlinggame, CA) was used as secondary antibody. Coverslips were washed three times in PBS and stained using an avidin-biotin-peroxidase (ABP) complex reaction (Vector Laboratories, Burlinggame, CA) for $30 \mathrm{~min}$ at room temperature and the peroxidase was visualized with diaminobenzidine (Wako, Tokyo) in PB.

\section{Loading of astrocytes with calcium indicator and caged calcium ionophore}

The cultures were incubated at $37^{\circ} \mathrm{C}$ for 60 min with the acetoxymethyl ester of fluo-3 (fluo-3-AM, $10 \mu$ M; Molecular probes, Eugene, OR) and $0.02 \%$ Pluronic F-127 (Sigma, St. Louis, MO). Fura-2 AM (excitation wavelengths 340 and $380 \mathrm{~nm}$ ) has been commonly used for determining the intracellular calcium concentration. However, caged calcium ionophore, DMNPE-caged Br A23187 (Molecular probes), is uncaged by the wave lengths of 330-385 nm light, and these wavelengths are the same range of fura-2 AM for the measurement of intracellular calcium. Therefore, in this study, we used fluo-3 (excitation wavelengths 480 and $500 \mathrm{~nm}$ ) for estimating the intracellular calcium concentration.

All experiments were performed in EBSS containing $1.5 \mathrm{mM} \mathrm{Ca}^{2+}$ and $1.5 \mathrm{mM} \mathrm{Mg}^{2+}$, supplemented with HEPES (25 mM) and D-glucose (5.5 mM), pH 7.3. Loading of astrocytes 
with caged calcium ionophore was done by incubating cells in EBSS containing $20 \mu \mathrm{M}$ DMNPE-caged $\mathrm{Br}$ A23187 for $15 \mathrm{~min}$ at $37^{\circ} \mathrm{C}$. In some experiments, $\mathrm{Ca}^{2+}-$ free EBSS containing 1 mM Ethylene glycol-bis ( $\beta$-aminoethlether)-N, N, N', N'-tetraacetic acid (EGTA; Sigma) was used.

\section{Calcium imaging and photolysis of caged compound}

After the loading of astrocytes with fluo-3 AM, the cultures were rinsed two times in experimental solutions, and allowed to de-esterify for an additional $15 \min$ at $37^{\circ} \mathrm{C}$. Fluorescent images were acquired at 2 sec intervals with a cooled CCD camera (C4880-80; Hamamatsu Photonics, Hamamatsu). An analysis of the acquired images was done with an image processing and measuring system (AQUACOSMOS; Hamamatsu Photonics). The control image (F0) was that of the target astrocyte $5 \mathrm{sec}$ before focal photolytic flash. Changes in the calcium concentration within the astrocytes were monitored by examining changes in the fluorescence intensity (F) of each cell relative to the control image. The relative fluorescence intensity $(\mathrm{F} / \mathrm{F} 0)$ was used for evaluating the astrocytic response.

DMNPE-caged $\mathrm{Br}$ A23187 was photolysed using an epifluorescence attachment on a microscope (IX-FRA-CAGED; Olympus, Tokyo) equipped with an electronic shutter. A 100 W mercury lamp was used as the light source. The shutter was mounted between the lamp housing and the main body to control the timing and duration of UV exposure via a computer-controlled shutter driver/timer ( $\Sigma$-65L; SIGMA KOKI, Tokyo). The light was filtered by a U-MWU (330-385 nm, peak $360 \mathrm{~nm}$ ) fluorescence cube, and attenuated before passage through an objective lens of an Olympus IX70 microscope. The duration of the 
photolytic flash was usually set at $1 \mathrm{sec}$, and this amount of UV light did not induce astrocytic cell death as confirmed by observing changes in cell morphology, and by staining cells with propidium iodide (PI).

The propagation of calcium waves was analyzed using a series of images taken at 2 sec intervals. Distances were measured from the center of the flashed circular area (diameter, 50 $\mu \mathrm{m}$ ) for uncaging DMNPE-caged $\mathrm{Br}$ A23187. The arrival of the calcium wave front was defined as a rise of relative fluorescent intensity above 1.20. In some experiments, the conductance of gap junction channels between astrocytes was reduced by 12-doxyl stearic acid (DSA), which is known to reversibly block gap channels formed by connexin43 (Cx43) (Burt 1989), and by 2-Bromo-2-chloro-I, I, I, trifluorothane (halothane) (Fujita et al. 1998). In addition, a wide spectrum P2Y purinoceptors blocker, suramin (Scemes et al. 2000), a competitive antagonist at $\mathrm{IP}_{3}$ receptor, heparin (Idestrup et al. 1998), and a phospholipase $\mathrm{C}$ inhibitor, U-73122 (Venance et al. 1997; Willmott et al. 2000) were used to investigate whether previously suggested mechanisms for the initiation and propagation of calcium waves are also involved in the photolytic flash-induced calcium waves. Astrocytic cultures were incubated in EBSS containing $300 \mu \mathrm{M}$ DSA (Molecular Probes), $500 \mu \mathrm{M}$ halothane (Astra Zeneca, UK), $100 \mu$ M suramin (Sigma), $5 \mu$ M U-73122 (Calbiochem, San Diego, CA) or heparin (1mg/ml, Wako) for $15 \mathrm{~min}$ at $37^{\circ} \mathrm{C}$.

\section{Statistical analysis}

Data were statistically analyzed using Student's $t$-test as indicated in the text. P values $<$ 0.05 or 0.01 were considered as statistically significant differences. 


\section{Results}

An immunohistochemical analysis of 2- to 3-week cell cultures revealed that MAP-2-positive cells composed less than $5 \%$ of the population, and thus more than $95 \%$ of cells were GFAP-positive astrocytes. Figure 1 shows an example of the results of such immunostaining. GFAP-positive astrocytes bore long-processes and had a nearly flat morphology (A \& C). In this example, a few MAP-2-positive neurons were identified, but other cells were stained only faintly with a MAP-2 antibody (B \& D).

\section{Photolytic flash-induced calcium waves}

We first determined the appropriate duration of flash for the photolysis of DMNPE-caged Br A23187 and investigated whether such photolytic flash could induce calcium waves to propagate in our astrocytic cultures. The photolytic flash of different durations was applied for uncaging caged calcium ionophore (Fig. 2). The photolytic flashes of 0.125 and 0.25 sec duration did not evoke marked rise in intracellular calcium both in the flashed astrocyte and in the neighboring cells (A \& B). The flash of 0.5 sec duration, however, evoked intracellular calcium increase in about $10 \%$ of astrocytes (C), and that of 1.0 sec duration evoked more than $50 \%$ of them (D) within a radius of $100 \mu \mathrm{m}$ from the center of the flashed area. When the duration of photolytic flash was longer than $1.0 \mathrm{sec}$, the second flash of same duration did not reproduce the calcium rise in astrocytes, probably because of the noxious effects of the flash light itself on cells. Therefore, in the following, we use the photolytic flash of 1.0 sec duration for evoking intercellular calcium waves in astrocytic culture. Figure 3 shows an example of 
such results. The flashed area is indicated by a red circle (diameter; $50 \mu \mathrm{m}, \mathrm{A} 2$ ). The intracellular calcium increase then propagated to neighboring astrocytes (cell $2 \backsim 6$ in A2 \& B). Propagating calcium waves were evoked in more than $50 \%$ of the astrocytic cultures tested.

We then analyzed the relationship between the distance from the center of the flashed area and the time of the calcium response in other astrocytes. Figure 4 summarizes the data from 34 cells in 7 cultures. There was a tendency for the delay in the calcium response to increase as the distance increased. The mean propagation velocity of the calcium waves calculated from the linear regression line was about $4.12 \mu \mathrm{m} / \mathrm{s}$.

\section{Extracellular calcium influx is required for wave induction}

We demonstrated here that propagating calcium waves could be evoked by photolysis of a caged calcium ionophore. However, there remains a possibility that the UV light flash for uncaging the ionophore affects the cell metabolism and causes the increase in intracellular calcium. Thus, we then investigated whether the photolytic flash itself induces a calcium response, and whether the influx of extracellular calcium into the flashed cell would be required for the induction of the waves (Fig. 5). The fluorescence ratio images show the intracellular calcium of the flashed cell at two different time points; just (A1, B1 and C1) and 30 sec (A2, B2 and C2) after the photolytic flash. Relative fluorescence intensity in D represents the intracellular calcium response of the same cell indicated by an arrows. The photolytic flash resulted in a rapid increase in intracellular calcium when DMNPE-caged $\mathrm{Br}$ A23187 was present in the experimental solution (A1, A2 and red curve in D). However, the photolytic flash itself did not induce a detectable increase in calcium when DMNPE-caged Br A23187 was 
absent (B1, B2 and blue curve in D). In addition, the flash did not induce a response in the calcium-free solution even when DMNPE-caged $\mathrm{Br}$ A23187 was present (C1, C2 and green curve in D). These results led us to the conclusion that the photolytic flash had nothing to do with the calcium response, and that the influx of extracellular calcium caused by the uncaged calcium ionophore is necessary for the induction of waves. The loading of astrocytes with DMNPE-caged Br A23187 without a photolytic flash did not induce a calcium response (data not shown).

\section{Calcium waves are not caused by diffusion of uncaged calcium ionophore}

Although our results clearly indicate that the uncaging of DMNPE-caged Br A23187 was crucial for the wave induction, there remains the possibility that the uncaged, activated calcium ionophore diffuses around the flashed area, and then increases intracellular calcium in the neighboring astrocytes. Therefore, we tested this possibility.

Focally evoked calcium waves in astrocyte culture have been thought to propagate by gap junction-mediated intercellular passage of chemical signals (Hassinger et al. 1996), and by ATP releasing from stimulated astrocytes (Guthrie et al. 1999). We investigated whether the wave propagation occurs when both gap junction channels between astrocytes and purinergic receptors were blocked (Fig. 6). Propagating calcium waves were evoked by photolysis of a caged calcium ionophore (A). However in the presence of $300 \mu \mathrm{M}$ DSA, a reversible blocker of gap junction channels, and $100 \mu \mathrm{M}$ suramin, a purinergic receptor antagonist, the wave propagation was markedly inhibited (B). The mean control ratio increase, an average of the two ratio increase evoked by two photolytic flashes separated by 20 min, was $143.8 \pm$ 
$22.4 \%$ (mean $\pm \mathrm{SD}, \mathrm{n}=9$, different cultures) (D). In contrast, treatment of astrocytes with DSA and suramin resulted in the significant decrease in the mean ratio increase; $108.6 \pm 8.9 \%$ ( $\mathrm{n}=6$, different cultures, $\mathrm{p}<0.01)(\mathrm{D})$. The wave propagation recovered when DSA and suramin were washed-out (data not shown). These results suggested that gap junction channels and/or purinergic receptors were responsible for the propagation of calcium waves, and that the calcium waves described in this study were not caused by the diffusion of uncaged calcium ionophore around the flashed area.

To confirm further that calcium wave propagation was not caused by diffusion of uncaged calcium ionophore, we analyzed the change of calcium wave propagation evoked by photolytic flash of caged calcium ionophore by treatment of cultures with different blockers or inhibitors of astrocytic calcium waves. In the presence of $300 \mu \mathrm{M}$ DSA or $500 \mu \mathrm{M}$ halothane, the blocker of gap junctions, and $1 \mathrm{mg} / \mathrm{ml}$ heparin, the specific antagonist of $\mathrm{IP}_{3}$ receptor, the ratio increase of intracellular calcium in neighboring astrocytes within a radius of $100 \mu \mathrm{m}$ from the center of the flashed area significantly decreased compared with that of control (Fig. 7). The ratio increase of calcium decreased to $109.8 \pm 9.0 \%$ ( $n=5$, different cultures, $\mathrm{p}<0.01), 117.7 \pm$ $13.4 \%(\mathrm{n}=4$, different cultures, $\mathrm{p}<0.05)$ and to $105.6 \pm 6.0 \%(\mathrm{n}=5$, different cultures, $\mathrm{p}<$ 0.01) in the presence of DSA, halothane and heparin, respectively.

\section{Phospholipase C activation necessary for initiation of calcium waves}

A previous study (Venance et al. 1997) has demonstrated that either mechanical stimulation or focal application of ionomycin, a calcium ionophore, evokes propagating calcium waves in astrocytic cultures. They postulated that activation of phospholipase C (PLC) is necessary for 
the initiation and propagation of intercellular calcium waves. We then investigated whether PLC activation was also crucial for the induction of photolytic flash-induced calcium waves described here (Fig. 8).

Propagating calcium waves were evoked by photolysis of a caged calcium ionophore. The photolytic flash of $1.0 \mathrm{sec}$ duration resulted in marked rise in intracellular calcium both in the flashed astrocyte (arrow in A2) and in neighboring cells (A2 \& A3). However, in the presence of $5 \mu \mathrm{M} \mathrm{U}-73122$, an inhibitor of PLC (Venance et al. 1997; Willmott et al. 2000), the photolytic flash of same duration did not evoke appreciable rise in intracellular calcium both in the flashed cell, the same cell shown in A2 (arrow in B2), and in neighboring cells (B2 \& B3). The mean ratio increase significantly decreased $(n=4$, different cultures, $\mathrm{p}<0.01)$ in the presence of U-73122 (D). These results suggested that PLC activation was necessary for the initiation of propagating astrocytic calcium waves evoked by photolysis of caged calcium ionophore.

\section{Conduction distance and velocity of calcium waves}

We then investigated whether and how the conduction distance and velocity of photolytic flash-induced intercellular calcium waves changed in the presence of blockers of gap junctions or a purinergic receptor antagonist (Fig. 9). The conduction distance was defined as a distance between the center of the flashed area and that of the cell in which calcium response; that is, a rise of relative fluorescent intensity above 1.20 was observed. The conduction distance was significantly reduced when the cultures were treated either with DSA or halothane (A). However, treatment with suramin, a purinergic receptor antagonist, did not result in the 
significant reduction in the conduction distance (A). Co-treatment with suramin and DSA reduced the conduction distance of calcium waves. The conduction velocity was also reduced significantly when the cultures were treated either with DSA or halothane (B). However, suramin treatment did not evoke significant changes in the conduction velocity (B). The concentration of suramin used here (100 $\mu \mathrm{M})$ seemed to be sufficient for the inhibition of the propagation of calcium waves evoked by mechanical stimulation (Willmott et al. 2000). These results suggested a possibility that the release of ATP and purinoceptors were not critically involved in the propagation of calcium waves evoked by photolysis of caged calcium ionophore, and that functional gap junctions were crucial for the wave propagation. In fact, in the presence of DSA, a reversible blocker of gap junctions (Kawahara et al. 2002; Yamauchi et al. 1996), markedly suppressed the propagation of photolytic flash-induced calcium waves (Fig. 10). In the same culture shown in Fig. 3, the photolytic flash of 1.0 sec duration evoked marked rise in intracellular calcium in the flashed astrocyte (cell 1), but did not in the neighboring cells other than cell 2 (A \& B). This result suggested that the suppressive effects on wave propagation induced by co-treatment with DSA and suramin (Fig. 6) were primarily due to the reduced gap junctional permeability caused by DSA, not to the blocking of purinergic receptors by suramin. 


\section{Discussion}

This study demonstrated that focal photolysis of a caged calcium ionophore resulted in waves of increase in intracellular calcium in cultured astrocytes from newborn rats. The influx of extracellular calcium into the photolytically flashed astrocyte and functional gap junction channels between cells were required for the initiation and propagation, respectively, of the calcium waves. Biochemically undefined mechanical stimulation has been commonly used to initiate or trigger calcium waves in cultured astrocytes. In contrast, the origin of the calcium waves seems clear in the present method; that is, influx from the extracellular environment.

Previous studies (Beyer et al. 1990; Dermietzel et al. 1991; Scemes et al. 2000) have revealed that astrocytes are coupled to each other by gap junction channels formed mainly by connexin43 (Cx43), and Cx43 channels contribute to about $95 \%$ of total junctional conductance. Intercellular passage of chemical signals such as calcium and $\mathrm{IP}_{3}$ are required for the propagation of waves (Boitano et al. 1992; Hassinger et al. 1996). In addition to the intercellular communication via gap junction channels, recent findings (Hassinger et al. 1996; Cotrina et al. 1998; Guthrie et al. 1999) have shown that there exists an extracellular communication system, in which ATP is utilized as the messenger. Local application of ATP evoked calcium waves and intracellular calcium was decreased by administration of purinergic receptor antagonists in cultured astrocytes (Guthrie et al. 1999). However, the present results suggested that the extracellular ATP-purinoceptor signaling pathway did not primarily participate in the propagation of calcium waves evoked by photolysis of caged calcium ionophpre. 
Long-chain alcohols, heptanol and octanol, or an anesthetic halothane are commonly used to block gap junction channels (Cotrina et al. 1998; Fujita et al. 1998; Scemes et al. 2000). The mechanisms by which such substances alter the activity of gap junction channels remain unknown. The possibility exists that the blocking effects on gap junction channels of such substances are indirect, and mediated by the stimulation of intracellular second messengers, which subsequently cause uncoupling of cells (Burt 1989). In fact, there is evidence that octanol inhibits $\mathrm{IP}_{3}$-induced calcium release (IICR) (Deutsch et al. 1995), and halothane attenuates the formation of $\mathrm{IP}_{3}$ (Deutsch et al. 1995; Sill et al. 1991). Considering these additional drug actions, the dose-dependent decrease caused by octanol and halothane in the amplitude of the rise in intracellular calcium may be due to the inhibition of IICR in the cells themselves. In the present study, 12-doxyl stearic acid (DSA) and halothane were used to block gap junction channels between astrocytes. DSA has been known to rapidly and reversibly uncouple gap junction channels in a dose- and time-dependent manner (Burt 1989; Yamauchi et al. 1996). DSA-induced inhibition of gap junctional communication does not require a reduction of intracellular $\mathrm{pH}$ or $\mathrm{pCa}$ (Burt 1989). In addition, the drug action was completely reversible (Kawahara et al. 2002; Yamauchi et al. 1996), and DSA itself at the concentration used here (300 $\mu \mathrm{M})$ did not induce the death of astrocytes.

The present study revealed that focal photolysis of DMNPE-caged Br A23187 resulted in a focal increase in calcium in the flashed astrocyte. To date, caged- $\mathrm{IP}_{3}$ has been used for inducing focal increase in calcium. Photolysis of caged-IP $\mathrm{I}_{3}$ triggers the release of calcium from the intracellular pool and then increases the amount of intracellular calcium in cardiac myocytes (Jaconi et al. 2000) and in cerebellar Purkinje cells (Inoue et al. 1998). However, 
caged-IP ${ }_{3}$ must be directly microinjected into the cells. Intracellular microinjection itself sometimes results in damage to the cells. On the other hand, an acetoxymethyl ester of the photosensitive calcium chelator nitr-5 (caged calcium) has been used for inducing focal increases in intracellular calcium as well. This drug is easily introduced into cells like fluo-3/AM. The focal photolysis of this molecule results in a rapid increase in intracellular calcium (Gurney et al. 1987; Ashley et al. 1988; Lipp and Niggli 1998). Thus, focal photolysis of this caged compound may also result in intercellular calcium waves, although we failed to induce calcium waves in astrocytes in our preliminary experiments using this compound.

This study demonstrated that the shorter duration of flash less than $1.0 \mathrm{sec}$ for the photolysis of caged calcium ionophore could not evoke intercellular calcium waves effectively (Fig. 2). The flash of short duration induced only a transient rise in intracellular calcium in the flashed astrocyte. In contrast, the flash of 1.0 sec duration resulted in the persistent rise in calcium in the flashed cell, and in the propagation of calcium waves. In addition, the rise in intracellular calcium in the neighboring cells also persisted for long duration. These results suggested that the persistent rise in intracellular calcium in astrocytes was necessary for the initiation and propagation of intercellular calcium waves elicited by photolysis of caged calcium ionophore.

The present study has shown that activation of phospholipase C (PLC) was crucially responsible for the initiation of calcium waves (Fig. 8). Treatment of cultures with $5 \mu \mathrm{M}$ U-73122, an inhibitor of PLC (Venance et al. 1997; Willmott et al. 2000), markedly reduced the rise in intracellular calcium in the flashed astrocyte, and inhibited propagation of calcium waves. The PLC inhibition unexpectedly resulted in the marked reduction in the rise in calcium in the 
flashed cell, suggesting that the $\mathrm{Ca}^{2+}$ influx induced by uncaged calcium ionophore was relatively small. This means that most of the rise in intracellular calcium in the flashed cell observed in this study was resulted from $\mathrm{Ca}^{2+}$-dependent increase in intracellular calcium. The exact mechanism for this $\mathrm{Ca}^{2+}$-dependent $\mathrm{Ca}^{2+}$ increase is unclear at present, but one of the possibilities is that the rapid $\mathrm{Ca}^{2+}$-dependent activation of PLC leading to the increased production of IP3 (Venance et al. 1997) would result in the increased $\mathrm{Ca}^{2+}$ release from the intracellular calcium store.

Willmott et al. (2000) as well as our preliminary study have revealed that the possible involvement of NO-cGMP dependent protein kinase signaling pathway in the regulation of astrocytic calcium waves. NO-cGMP signaling pathway activates ryanodine receptor-linked calcium release from endoplasmic reticulum (ER) and is involved in the generation and propagation of intercellular calcium waves in astrocytes. Further studies will be needed to clarify as to how endogenously produced NO affects calcium uptake or release in ER, and the propagation of calcium waves.

In conclusion, this study highlights that calcium waves can be evoked by focal photolysis of caged calcium ionophore in cultured astrocytes from newborn rats. Both the conduction distance and conduction velocity seemed to be markedly different from those in the previously described calcium waves evoked by mechanical or electrical stimulation. In addition, the extracellular ATP-purinoceptor signaling pathway did not primarily contribute to the propagation of calcium waves evoked by photolysis of caged calcium ionophpre. This method seems to provide a new in vitro model for the analysis of intercellular calcium waves. 


\section{Acknowledgements}

The authors thank Dr. Takayuki Nakajima, Research Institute for Electronic Science, Hokkaido University, for advice on the immunostaining of cells. 


\section{References}

Ashley CC, Bansotti RJ, Ferenczi MA, Lea TJ, Mulligan IP (1988) Thin filament activation by photolysis of caged calcium in skinned muscle fibers from the frog. Biophys J 53:564a

Beyer EC, Paul DL, Goodenough DA (1990) Connexin family of gap junction proteins. J Mem Biol 116:187-194

Boitano S, Dirksen ER, Sanderson MJ (1992) Intercellular propagation of calcium waves mediated by inositol triphosphate. Science 258:292-295

Burt JM (1989) Uncoupling of cardiac cells by doxyl stearic acid: specificity and mechanism of action. Am J Physiol 256:C913-C924

Charles A (1998) Intercellular calcium waves in glia. Glia 24:39-49

Cornell-Bell AH, Finkbeiner SM, Cooper MS, Smith SJ (1990) Glutamate induces calcium waves in cultured astrocytes: long range glial signaling. Science 247:470-473

Cotrina ML, Lin JH-C, Alves-Rodriguos A, Liu S, Li J, Azmi-Ghadimi H, Kang J, Naus CCG, Nedergaard M (1998) Connexins regulate calcium signaling by controlling ATP release. Proc Natl Acad Sci USA 95:15735-15740 
Cotrina ML, Lin JH-C, Lopez-Garcia JC, Naus CCG, Nedergaard M (2000) ATP-mediated glia signaling. J Neurosci 20:2835-2844

Dani JW, Chernjavsky A, Smith SJ (1992) Neuronal activity triggers calcium waves in hippocampal atrocyte networks. Neuron 8:429-440

Dermietzel R, Hertberg EL, Kessler JA, Spray DC (1991) Gap junctions between cultured astrocytes: Immunocytochemical, molecular, and electrophysiological analysis. J Neurosci 11:1421-1432

Deutsch DE, Williams JA, Yule DI (1995) Halothane and octanol block $\mathrm{Ca}^{2+}$ oscillations in pancreatic acini by multiple mechanisms. Am J Physiol 269:G779-G788

Fam SR, Gallagher CJ, Salter MW (2000) P2Y purinoceptor-mediated $\mathrm{Ca}^{2+}$ signaling and $\mathrm{Ca}^{2+}$ wave propagation in dorsal spinal cord astrocytes. J Neurosci 20:2800-2808

Fujita K, Nakanishi K, Sobue K, Ueki K, Asai T, Kato T (1998) Astrocytic gap junction blockage and neuronal $\mathrm{Ca}^{2+}$ oscillation in neuron-astrocyte cocultures in vitro. Neurochem Int 33:41-49

Gurney AM, Tsien RY, Lester HA (1987) Activation of a potassium current by rapid photochemically generated step increases of intracellular calcium in rat sympathetic neurons. 
Proc Natl Acad Sci 84:3496-3500

Guthrie PB, Knappenberger J, Segal M, Bennett M VL, Charles AC, Kater SB (1999) ATP released from astrocytes mediates glial calcium waves. J Neurosci 19:520-528

Hassinger TD, Atkinson PB, Strecker GJ, Whalen LR, Dudek FE, Kossel AH, Kater SB (1995) Evidence for glutamate-mediated activation of hippocampal neurons by glial calcium waves. J Neurobiol 28:159-170

Hassinger TD, Guthrie PB, Atkinson PB, Bennet MVL, Kater SB (1996) An extracellular signaling component in propagation of astrocytic calcium waves. Proc Natl Acad Sci USA 93:13268-13273

Inoue T, Kato K, Kohda K, Mikoshiba K (1998) Type1 inositol 1,4,5-triphosphate receptor is required for induction of long-term depression in cerebellar Purkinje neurons. J Neurosci 18:5366-5373

Idestrup CP, Salter MW (1998) P2Y and P2U receptors differentially release intracellular calcium via the phospholipase c/inositol 1,4,5-triphosphate pathway in astrocytes from the dorsal spinal cord. J Neurosci 86:913-923

Jaconi M, Bony C, Richands SM, Terzic A, Arnaudeau S, Vassort G, Ruceat M (2000) Inositol 
1,4,5-triphosphate directs $\mathrm{Ca}^{2+}$ flow between mitochondria and the endoplasmic / sarcoplasmic reticulum: a role in regulating cardiac autonomic $\mathrm{Ca}^{2+}$ spiking. Mol Biol Cell $11: 1845-1858$

John GR, Scemes E, Suadican:SO, Liu JSH, Charles PC, Lee SC, Spray DC, Brosnan CF (1999) IL-1 $\beta$ differentially regulates calcium waves propagation between primary human fetal astrocytes via pathways involving P2 receptors and gap junction channels. Proc Natl Acad Sci USA 96:11613-11618

Kawahara K, Abe R, Yamauchi Y, Kohashi M (2002) Fluctuations of contraction rhythm during simulated ischemia/reperfusion in cultured cardiac myocytes from neonatal rats. Biol Rhythm Res (in press)

Lipp P, Niggli E (1998) Fundamental calcium release events revealed by two-photon excitation photolysis of caged calcium in guinea-pig cardiac myocytes. J Physiol 508.3:801-809

Nedergaard M (1994) Direct signaling from astrocytes to neurons in cultures of mammalian brain cells. Science 263:1768-1771

Newman EA, Zahs KR (1998) Modulation of neuronal activity by glial cells in the retina. J Neurosci 18:4022-4028 
Paemeleire K, Leybaert L (2000) Ionic changes accompanying astrocytic intercellular calcium waves triggered by mechanical cell damaging stimulation. Brain Res 857:235-245

Parpura V, Basarsky T, Liu F, Jeftinija K, Jeftinija S, Haydon P (1994) Glutamate-mediated astrocyte-neuron signaling. Nature 369:744-747

Parpura V, Haydon PG (1999) UV photolysis using a micromanipulated optical fiber to deliver UV energy directly to the sample. J Neurosci Meth 87:25-34

Scemes E, Suadicani SO, Spray DC (2000) Intercellular communication in spinal cord astrocytes: fine tuning between gap junctions and P2 nucleotide receptors in calcium wave propagation. J Neurosci 20:1435-1445

Sill JC, Scott CU, Eskuri S, Dyke R, Van R, Tarra J (1991) Halothane inhibits agonist-induced inositol phosphate and $\mathrm{Ca}^{2+}$ signaling in A7r5 cultured vascular smooth muscle cells. Mol Pharmacol 40:1006-1013

Venance L, Stella N, Glowinski J, Giaume C (1997) Mechanism involved in initiation and propagation of receptor-induced intercellular calcium signaling in cultured rat astrocytes. J Neurosci 17:1981-1992

Wiesner B, Hagen V (1999) Measurement of intracellular $\mathrm{Ca}^{2+}$ changes using novel caged cyclic 
nucleotides and confocal scanning microscopy. J Photochem Photobiol B Biol 49:112-119

Willmott NJ, Wong K, Strong AJ (2000) A fundamental role for the nitric oxide-G-kinase signaling pathway in mediating intercellular $\mathrm{Ca}^{2+}$ waves in glia. J Neurosci 20:1767-1779

Yamauchi Y, Harada T, Nakamura T, Kawahara K (1996) Rhythm dynamics of spontaneously beating cardiac myocytes of neonatal rats in culture. Proc 2nd IMIA-IFMBE Internatl Workshop on Biosignal Interpret :52-55 


\section{Figure legends}

Fig. 1

Immunohistochemistry of GFAP and MAP-2. Almost all the cells in culture (2 weeks in vitro) were GFAP-positive (A \& C). A few MAP-2-positive neurons were observed, but other cells were MAP-2 negative (B \& D), showing that the cultures used in this study were nearly pure astrocytic ones. Scale bars both in B and D show $200 \mu \mathrm{m}$.

Fig. 2

Calcium responses in astrocytes to photolytic flash of different durations. Cultured astrocytes were loaded with calcium indicator, fluo-3/AM, and focal photolysis of caged calcium ionophore was performed by the flash of different duration; $0.125 \mathrm{sec}(\mathrm{A}), 0.25 \mathrm{sec}$ (B), $0.5 \mathrm{sec}(\mathrm{C})$ and $1 \mathrm{sec}(\mathrm{D})$ just (A1, B1, C1 and D1) and $30 \mathrm{sec}(\mathrm{A} 2, \mathrm{~B} 2, \mathrm{C} 2$ and D2) after the photolytic flash. The flashed area is indicated by a red circle. A scale bar is $100 \mu \mathrm{m}$ and a color bar on the upper right indicates the scale of ratio intensity. Intracellular calcium increases from dark blue to red through yellow.

Fig. 3

Astrocytic calcium waves triggered by focal photolysis of caged calcium ionophore. Cultured astrocytes were loaded with calcium indicator, fluo-3/AM, and focal photolysis was performed by the flash of 1.0 sec duration at the time indicated by an arrow in B. Propagating intercellular calcium waves induced by photolysis of caged calcium ionophore at six different 
time points; 20 sec before the photolytic flash (A1) and 5 sec (A2), 30 sec (A3), 60 sec (A4), 120 sec (A5) and 180 sec (A6) after the flash. Relative fluorescence intensity (B) reflecting intracellular calcium in A increases from dark blue to red through yellow. The flashed area is indicated by a red circle in A2. A scale bar is $100 \mu \mathrm{m}$. A color bar on the right indicates the scale of ratio intensity.

Fig. 4

Relationship between the distances from the flashed astrocyte and the delay of calcium response in neighboring cells. This figure summarizes the data from 34 cells in 7 cultures. The solid line indicates a linear regression line fitted to the data. There is a close relationship between the onset delay and the distance from the center of photolytic flash to the respective cells.

Fig. 5

Uncaging of caged calcium ionophore and influx of extracellular calcium are necessary for calcium waves. The fluorescence ratio images show the intracellular calcium of the flashed cell at two different time points; just (A1, B1 and C1) and 30 sec (A2, B2 and C2) after the photolytic flash. Relative fluorescence intensity in D represents the change of intracellular calcium with time in the same cell indicated by an arrow. Photolytic flash resulted in a rapid increase in intracellular calcium in the flashed astrocyte when caged calcium ionophore was present in the experimental solution (A1, A2 and red curve in D). The flash itself did not induce an appreciable response when caged ionophore was absent (B1, B2 and blue curve in D). 
In calcium-free conditions, photolytic flash did not evoke a calcium response even when caged ionophore was present (C1, C2 and green curve in D). A scale bar is $100 \mu \mathrm{m}$. A color bar on the upper right indicates the scale of ratio intensity. Intracellular calcium increases from dark blue to red through yellow.

Fig. 6

Photolytic flash-induced calcium waves are not caused by diffusion of uncaged calcium ionophore. Both astrocytic gap junction channels and purinoceptors were blocked by co-administration of DSA and suramin (See Method). Cultured astrocytes were loaded with calcium indicator, fluo-3/AM, and focal photolysis of caged calcium ionophore was performed without (A) or with $300 \mu$ M DSA and $100 \mu$ M suramin (B) just (A1, B1), 30 sec (A2, B2), and 60 sec (A3, B3) after the flash. Figure C shows the change of relative fluorescene intensity after the photolytic flash of a single astrocyte indicated by an arrow in A2 and B2. Figure $\mathrm{D}$ shows the mean ratio increase $\pm \mathrm{SD}$ of this cell from five independent experiments $\left({ }^{*} \mathrm{p}<0.01\right.$ vs control). The ratio increase reflecting the rise of intracellular calcium was significantly depressed in the presence of DSA and suramin . A scale bar is $100 \mu \mathrm{m}$. The flashed area is indicated by a pink circle in A1 and B1. A color bar on the right indicates the scale of ratio intensity. Intracellular calcium increases from dark blue to red through yellow.

Fig. 7

Change in calcium responses by treatment with DSA, halothane or heparin. Bars indicate 
the mean ratio increase of at least four independent experiments. Error bars indicate SD ${ }^{*} \mathrm{p}<$ 0.05, ${ }^{* *} \mathrm{p}<0.01$ vs control; $\left.\mathrm{n}=4-9\right)$.

Fig. 8

Phospholipase C activation crucial for the initiation of calcium waves. The activity of phospholipase C (PLC) was inhibited by treatment of cultures with $5 \mu \mathrm{M} \mathrm{U}-73122$. Cultured astrocytes were loaded with calcium indicator, fluo-3/AM, and focal photolysis of caged calcium ionophore was performed without (A) or with $5 \mu$ M U-73122 (B) just (A1, B1), 30 sec (A2, B2), and 60 sec (A3, B3) after the flash. Figure $C$ shows the change of relative fluorescene intensity with time after the photolytic flash of a single astrocyte indicated by an arrow in $\mathrm{A} 2$ and $\mathrm{B} 2$. Figure $\mathrm{D}$ shows the mean ratio increase $\pm \mathrm{SD}$ of this cell from four independent experiments $\left({ }^{*} \mathrm{p}<0.01\right.$ vs control). The ratio increase reflecting the rise of intracellular calcium was significantly depressed in the presence of U-73122. A scale bar is $100 \mu \mathrm{m}$ and a color bar on the upper right indicates the scale of ratio intensity. Intracellular calcium increases from dark blue to red through yellow.

Fig. 9

Changes in the conduction distance and velocity of calcium waves by treatnent with DSA, 
halothane, suramin, and co-treatment with DSA and suramin. The conduction distance was

significantly decreased by treatment either with DSA or halothane, but not by suramin (A).

The conduction velocity was also reduced significantly by treatment either with DSA or halothane, but not by suramin (B). Error bars indicate SD $\left({ }^{*} \mathrm{p}<0.05,{ }^{* *} \mathrm{p}<0.01\right.$ vs control; $n=4-9)$.

Fig. 10

Blocking of gap junctions sufficient for inhibiting the initiation and propagation of calcium waves. Astrocytic calcium waves were triggered by focal photolysis of caged calcium ionophore. Cultured astrocytes were loaded with calcium indicator, fluo-3/AM, and focal photolysis was performed by the flash of $1.0 \mathrm{sec}$ duration at the time indicated by an arrow in $\mathrm{B}$ in the presence of $300 \mu \mathrm{M}$ DSA, a reversible blocker of gap junctions. The fluo-3 fluorescence images are shown at six different time points; 20 sec before the photolytic flash (A1) and $5 \mathrm{sec}(\mathrm{A} 2), 30 \mathrm{sec}(\mathrm{A} 3), 60 \mathrm{sec}(\mathrm{A} 4), 120 \mathrm{sec}$ (A5) and $180 \mathrm{sec}$ (A6) after the flash. Relative fluorescence intensity (B) reflecting intracellular calcium in A increases from dark blue to red through yellow. The flashed area is indicated by a red circle in A2. A scale bar is 100 
$\mu \mathrm{m}$. A color bar indicates the scale of ratio intensity. The culture used here is the same as shown in Fig. 3. Note that treatment with DSA markedly inhibited the rise in intracellular calcium in neighboring cells other than cell 2, although the photolytic flash evoked the marked rise in calcium in the flashed cell (cell 1). 
A

B

C

D

8.

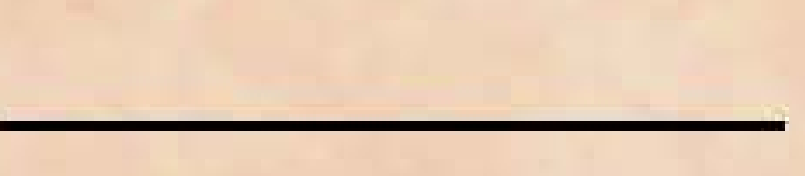



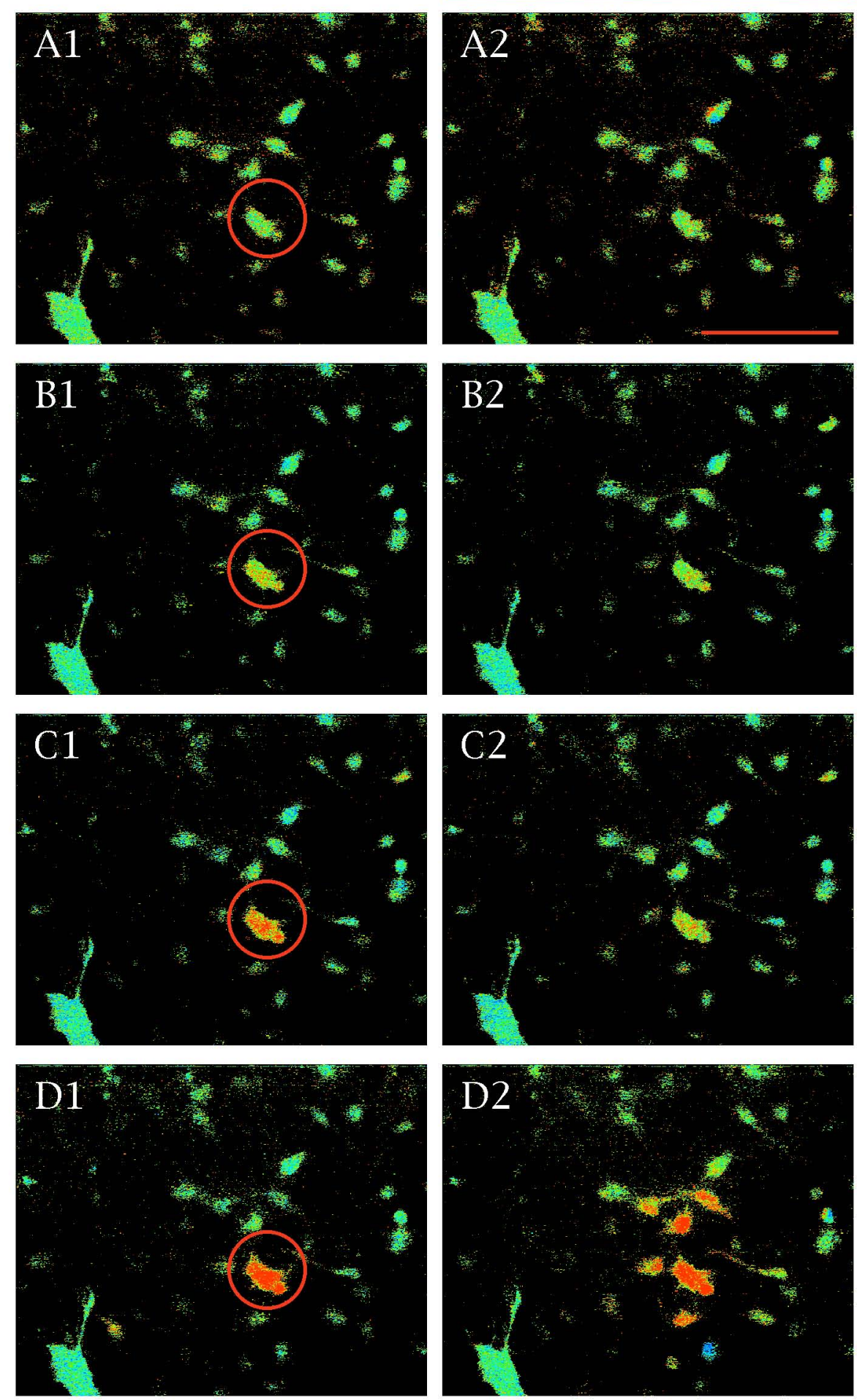

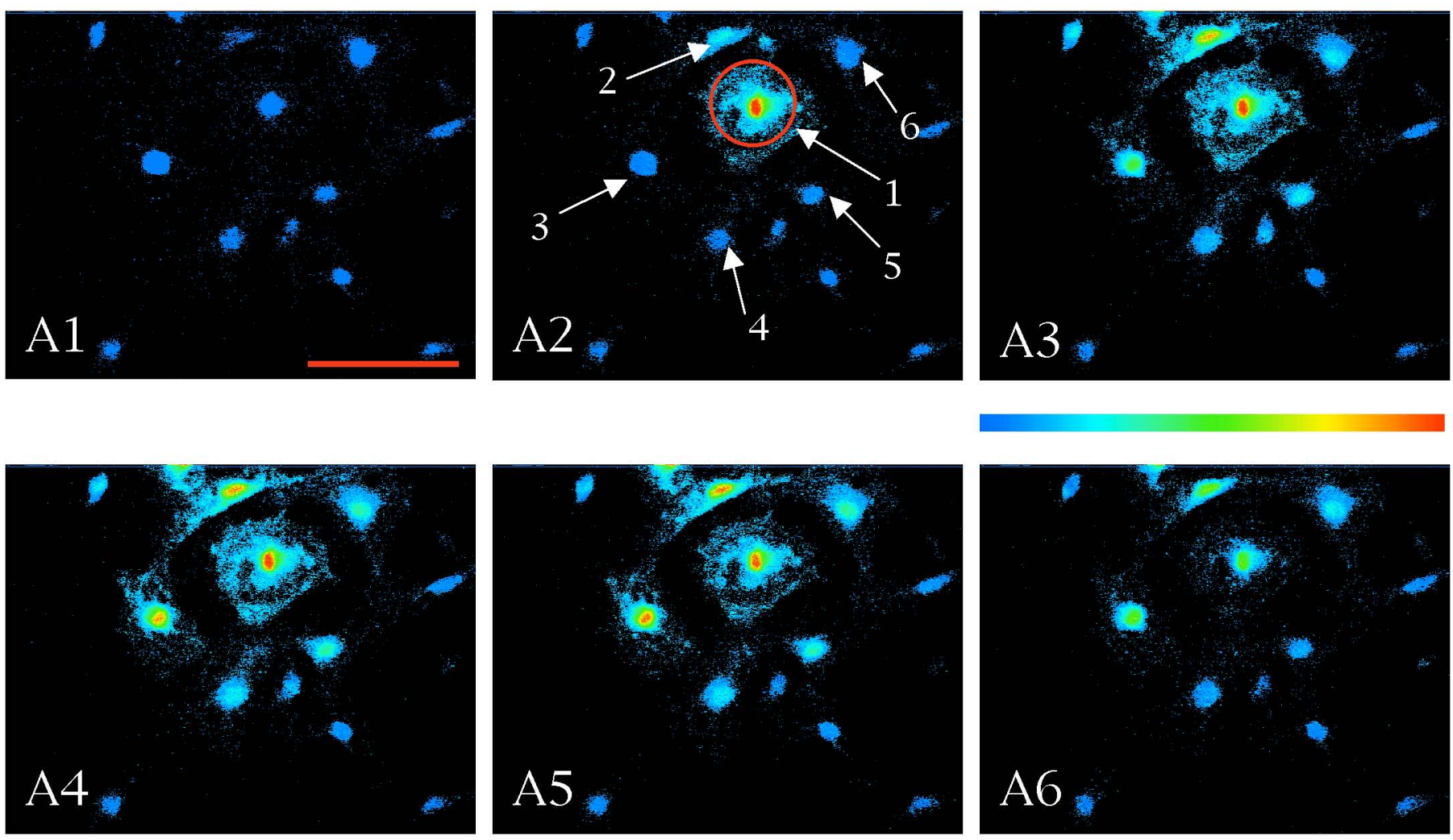

B

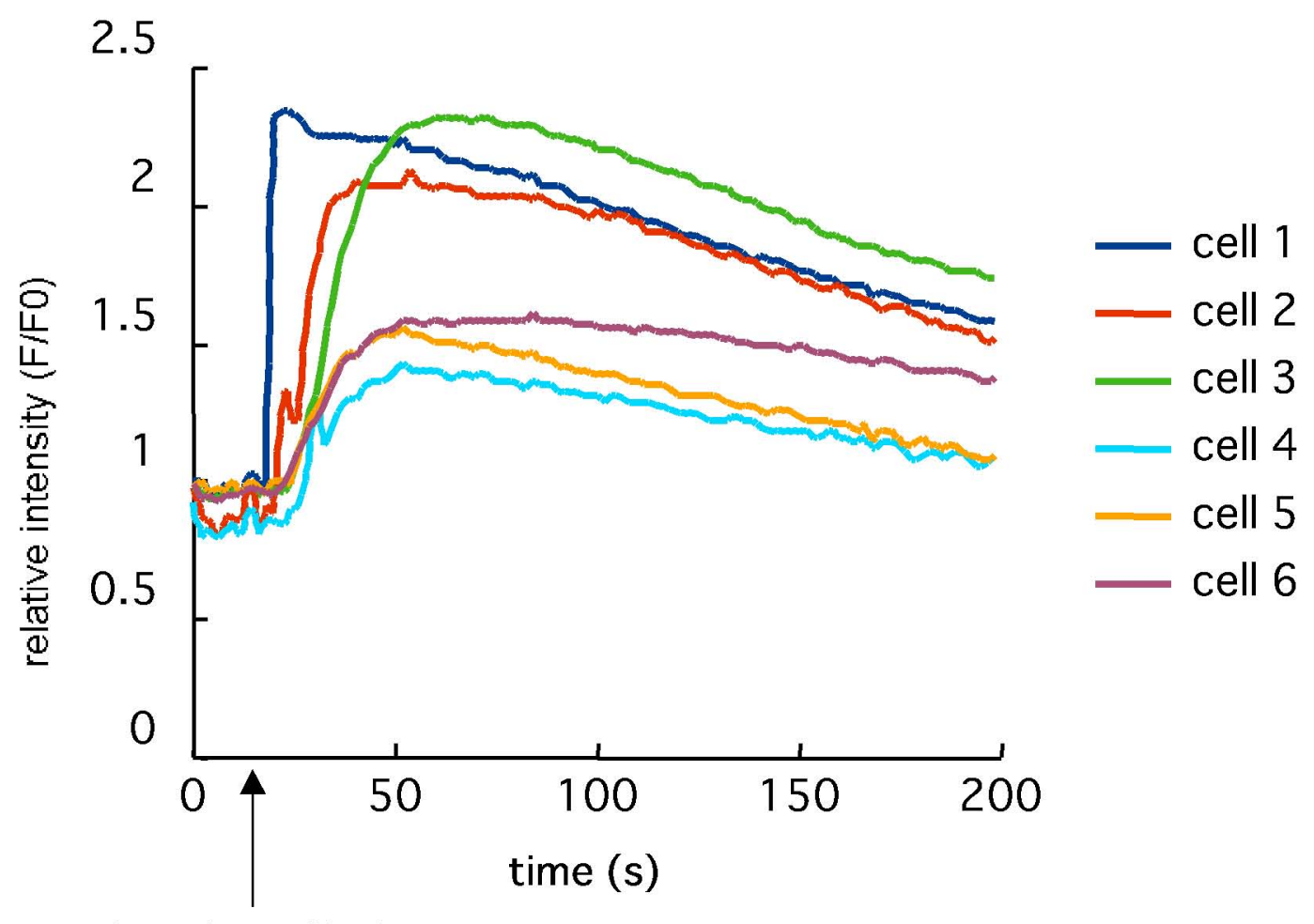

photolytic flash 


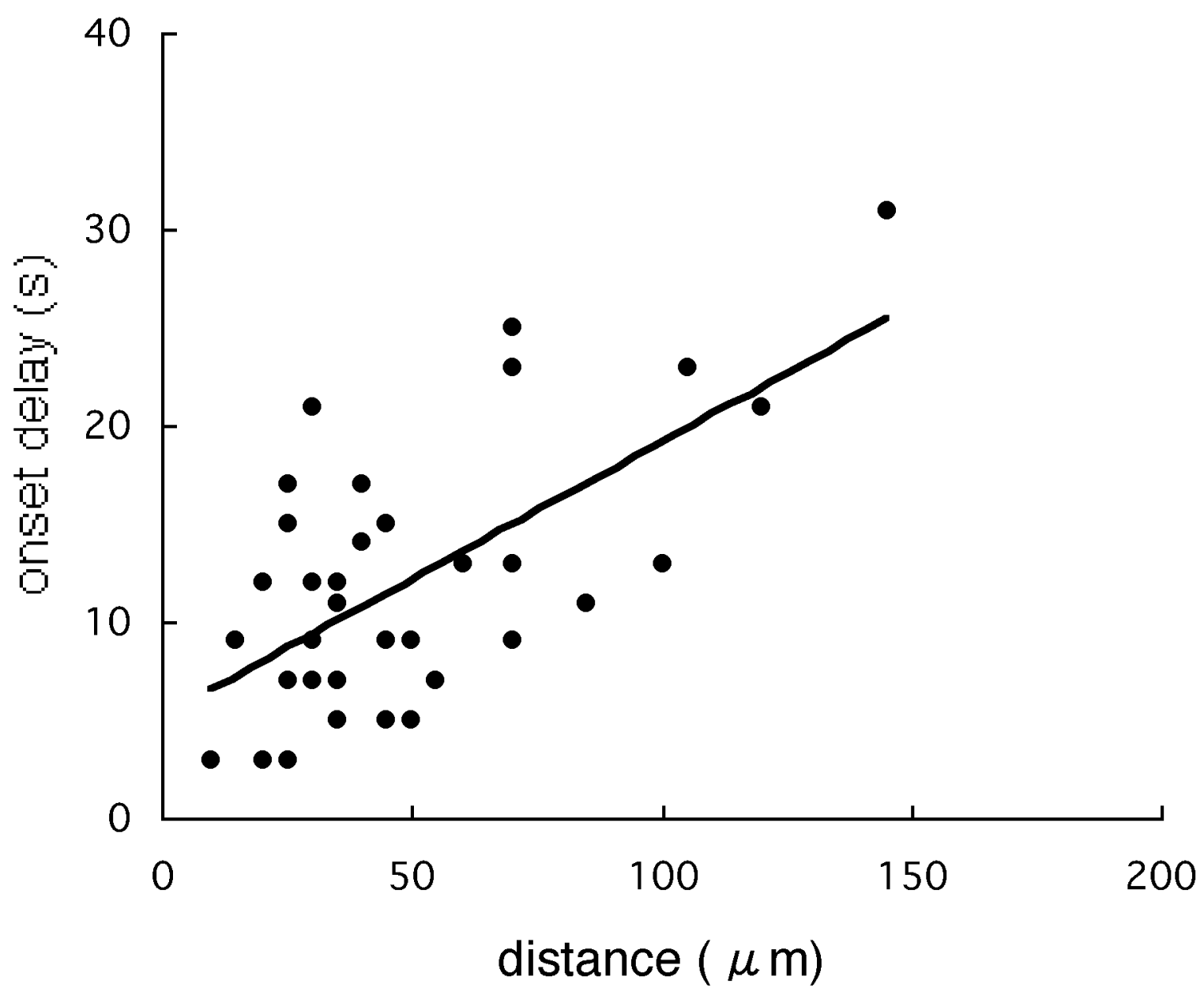



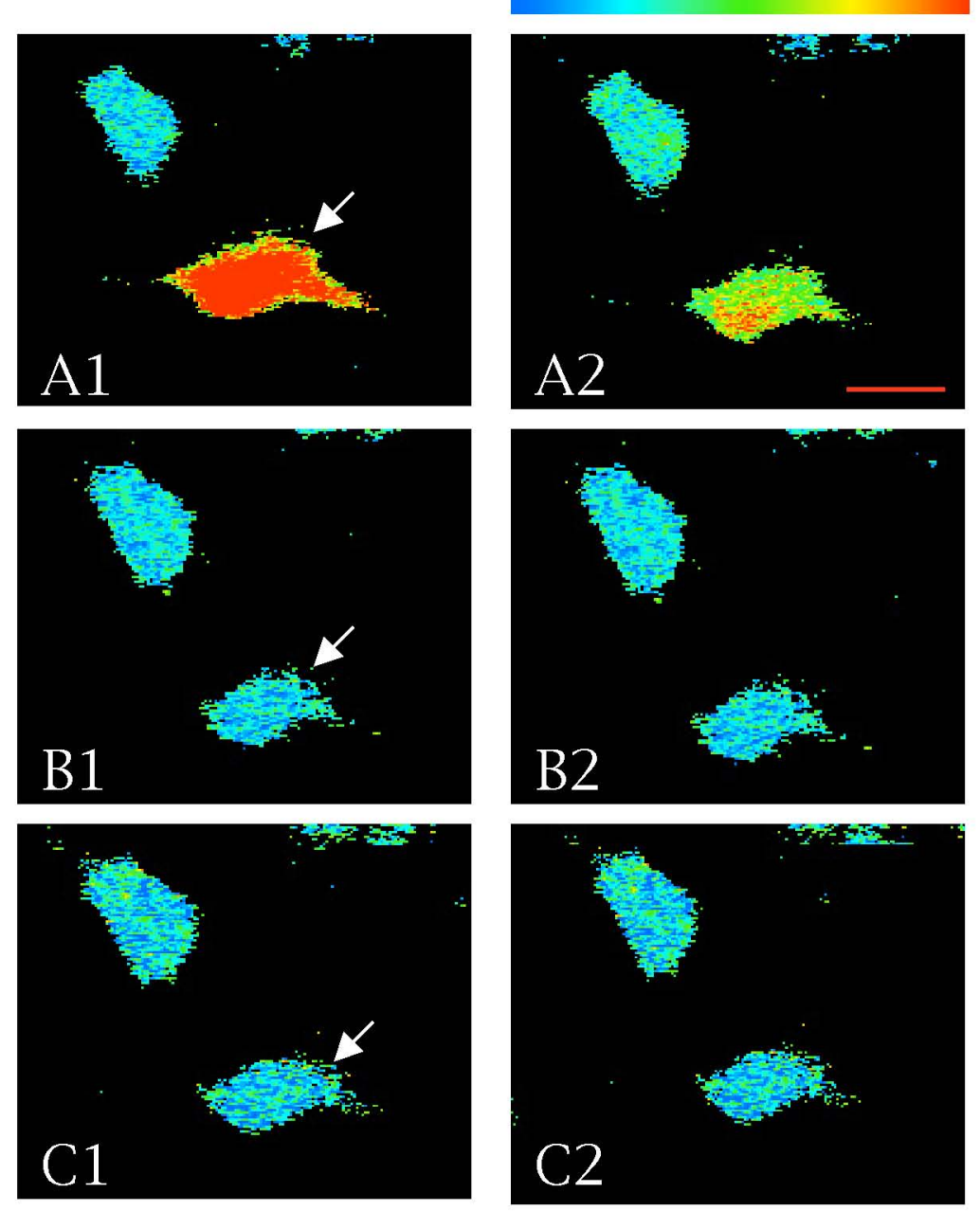

D

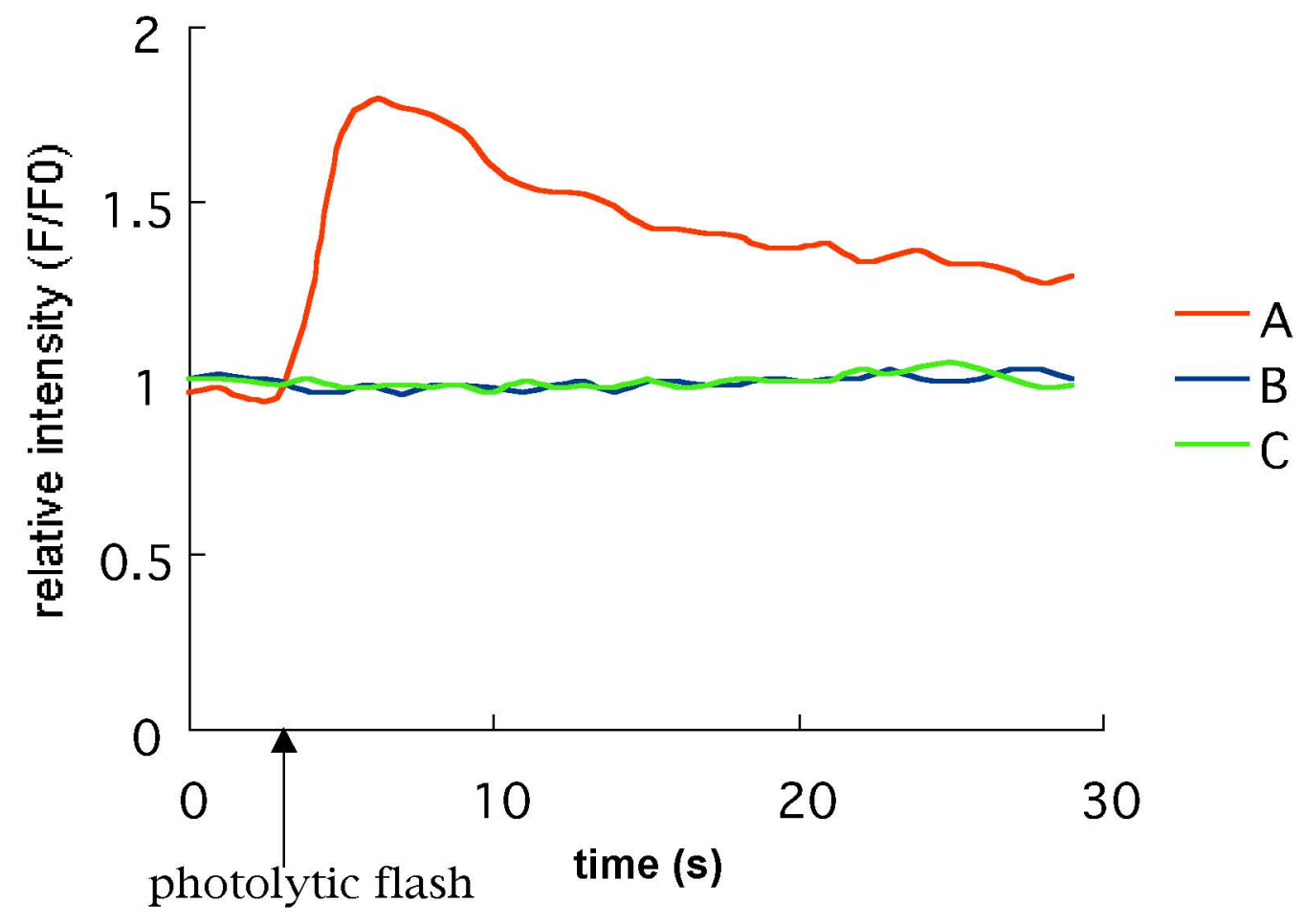




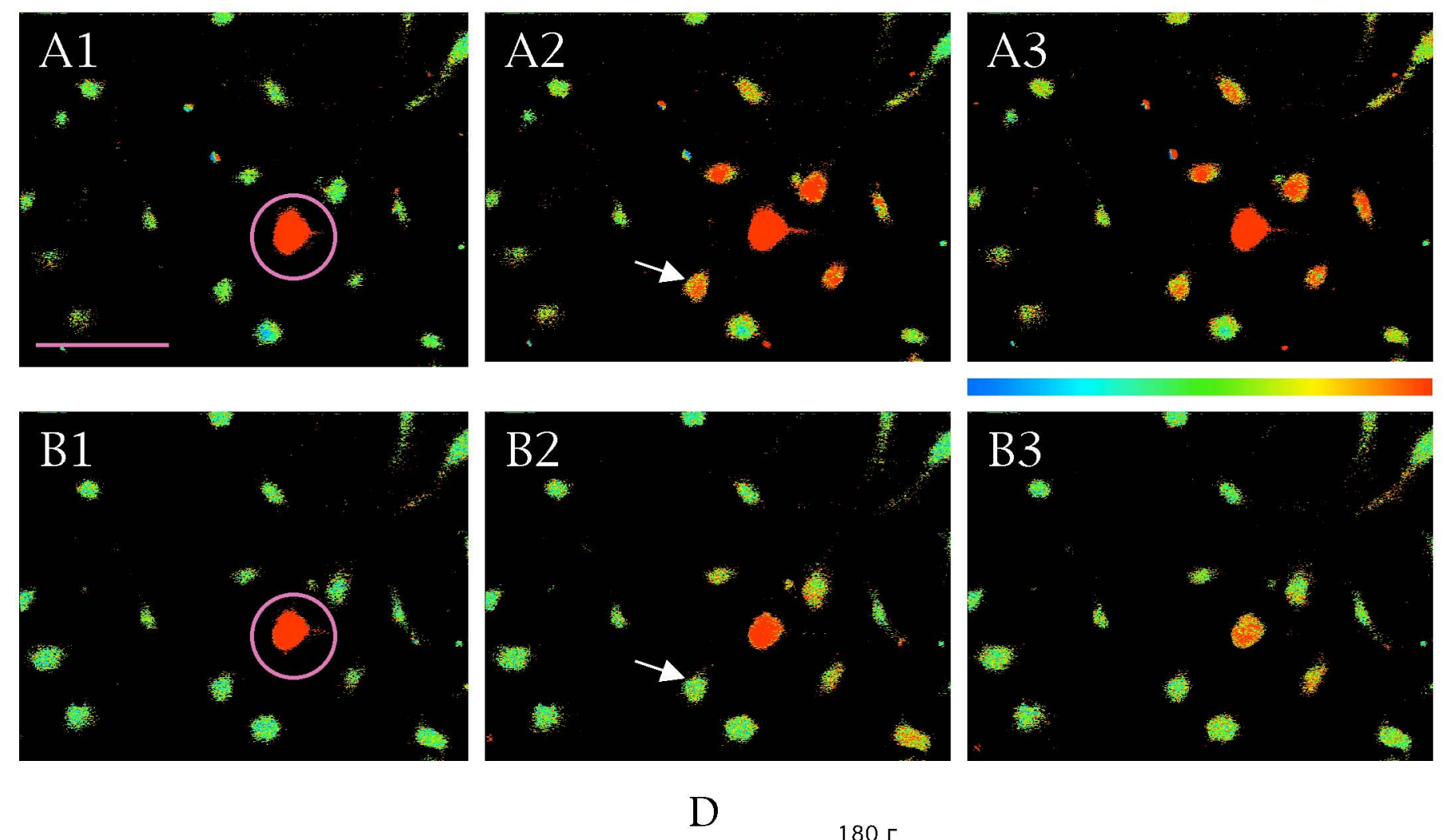

C

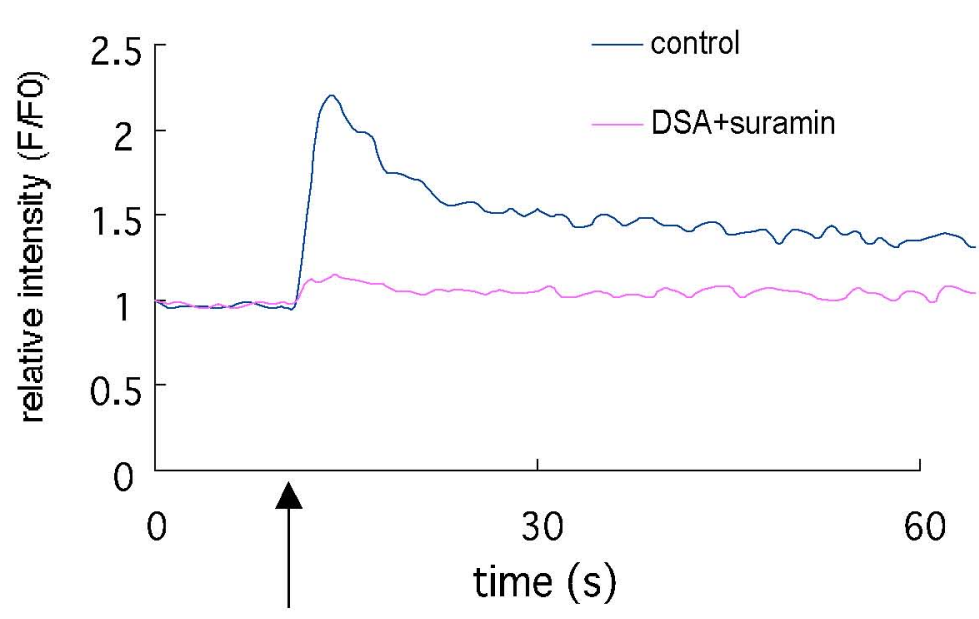

photolytic flash

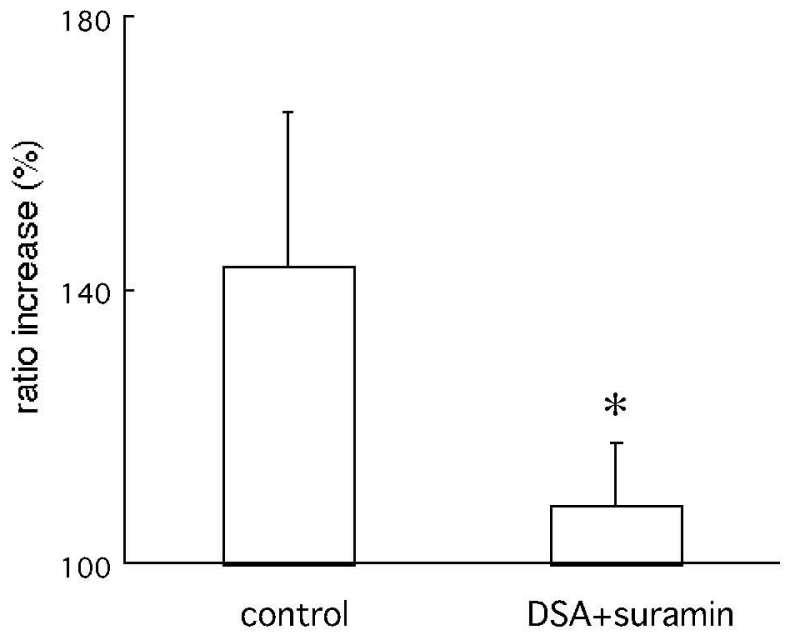




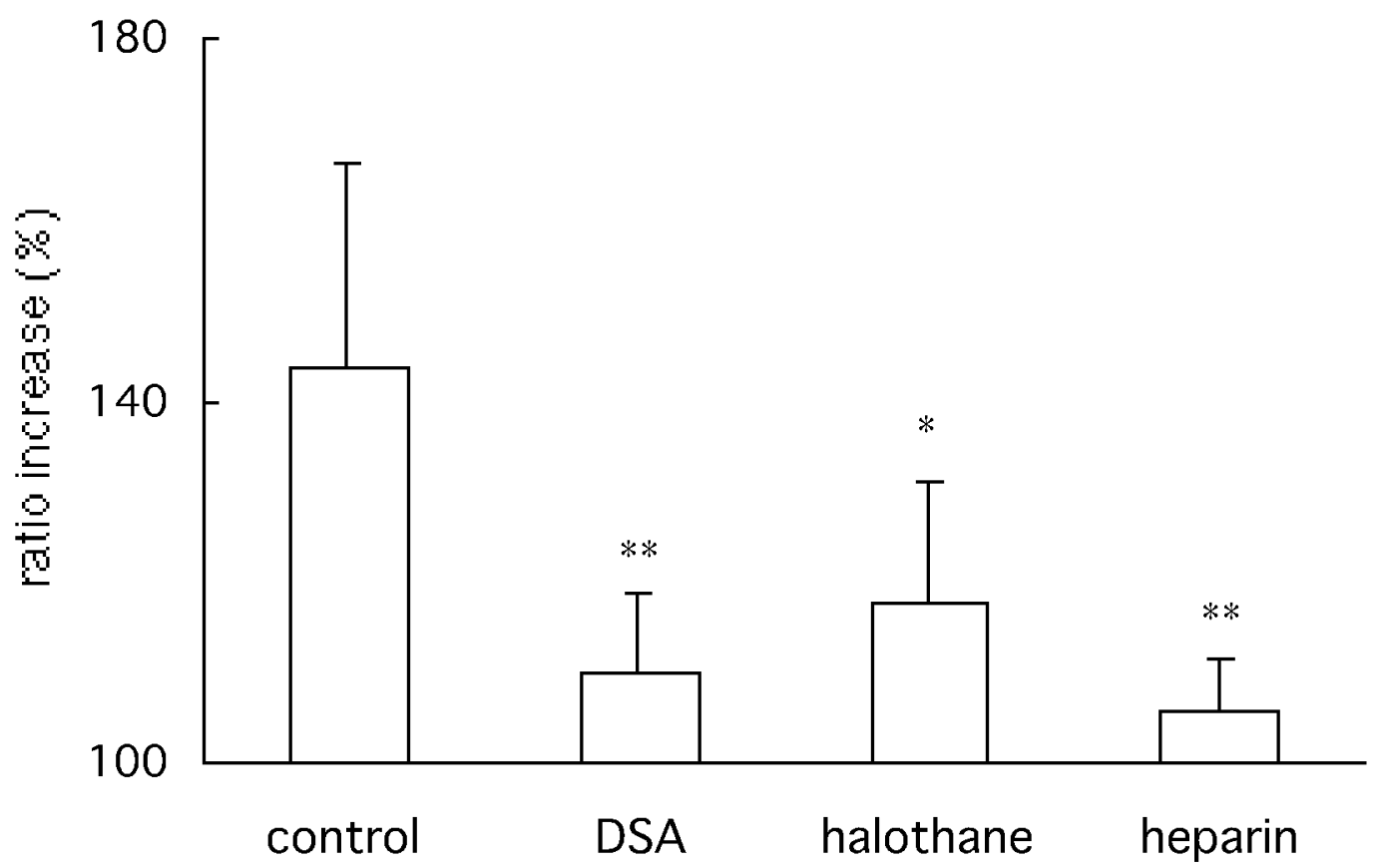



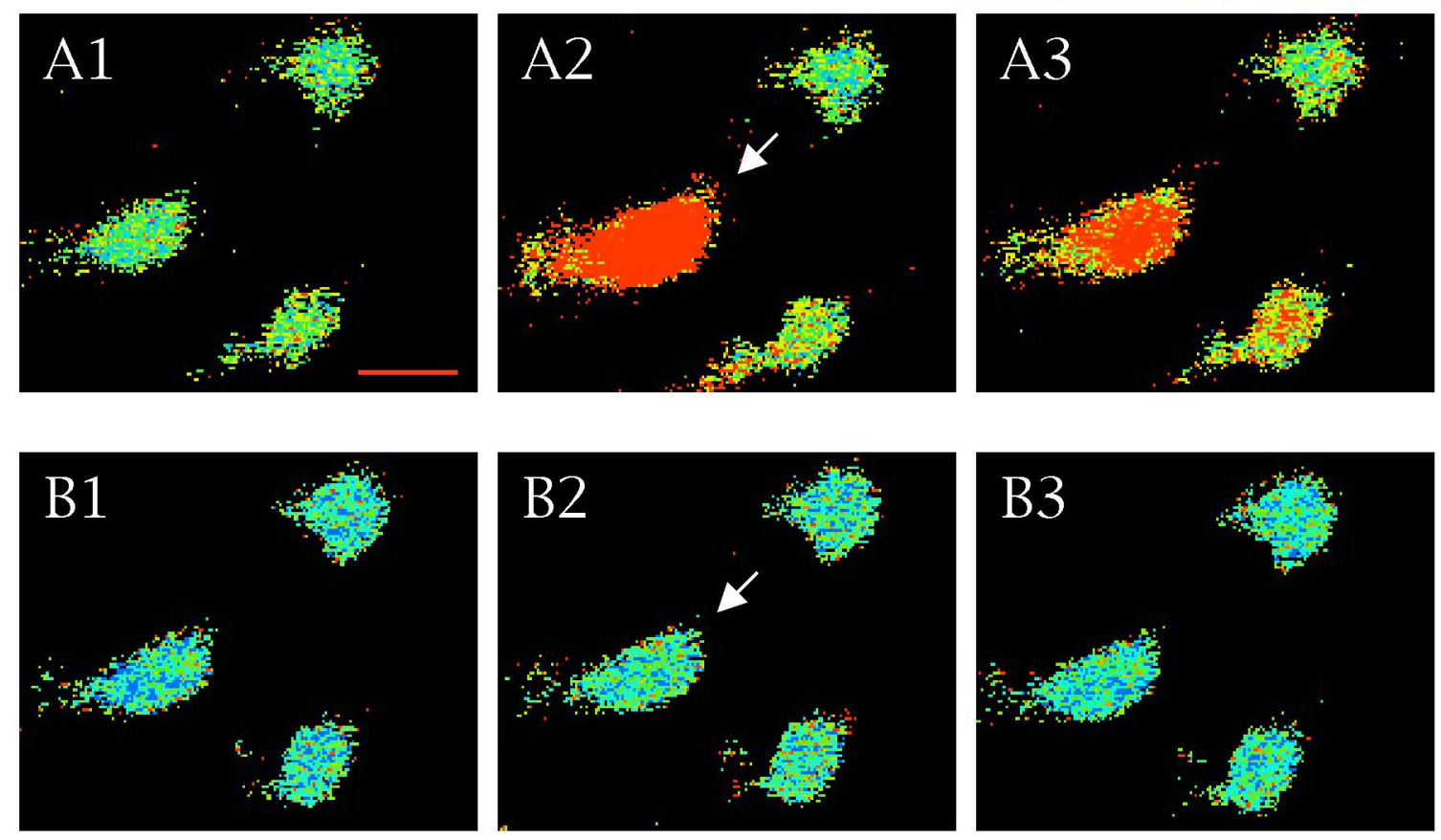

$C$

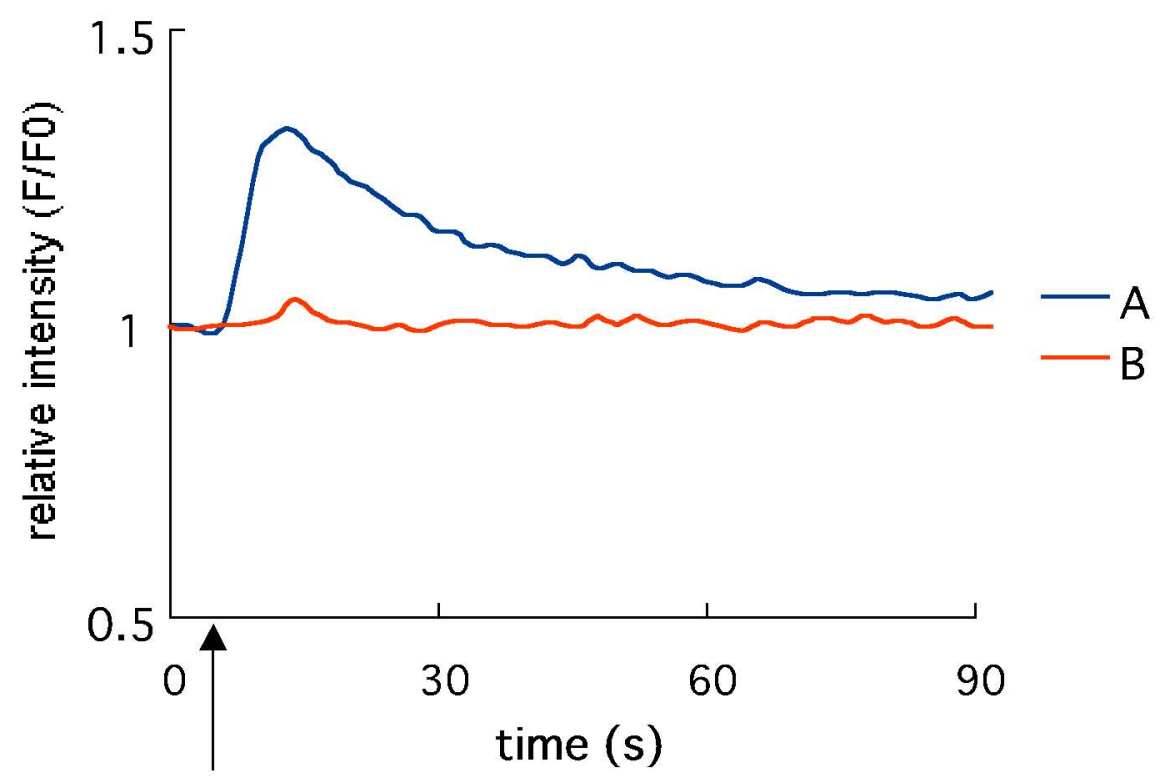

photolytic flash

D

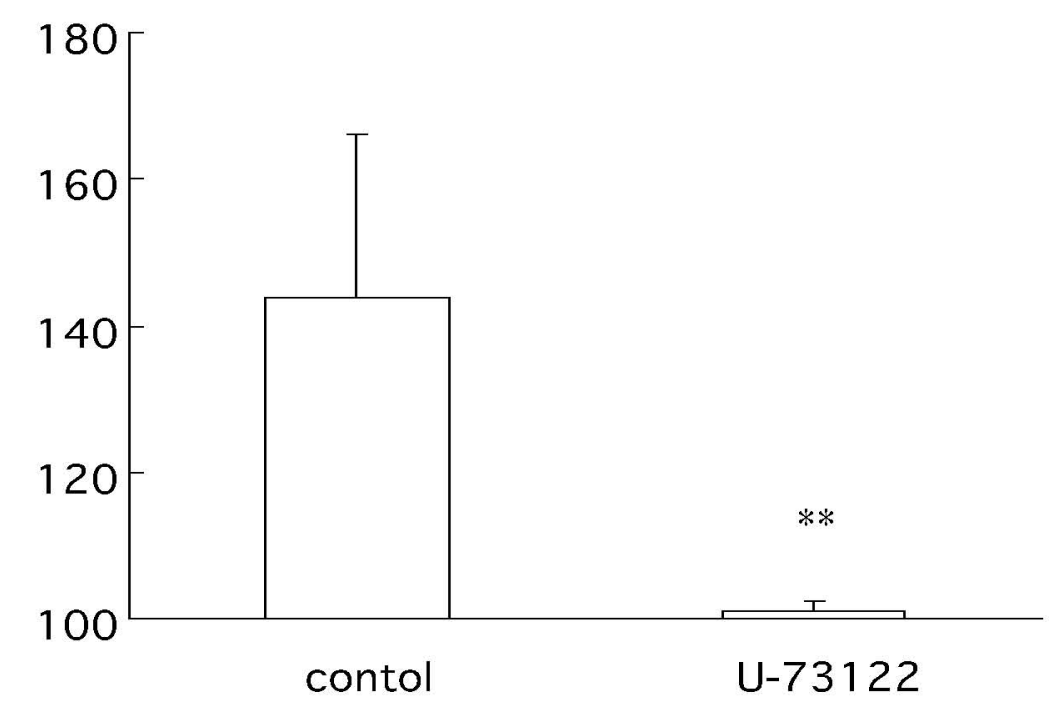


A

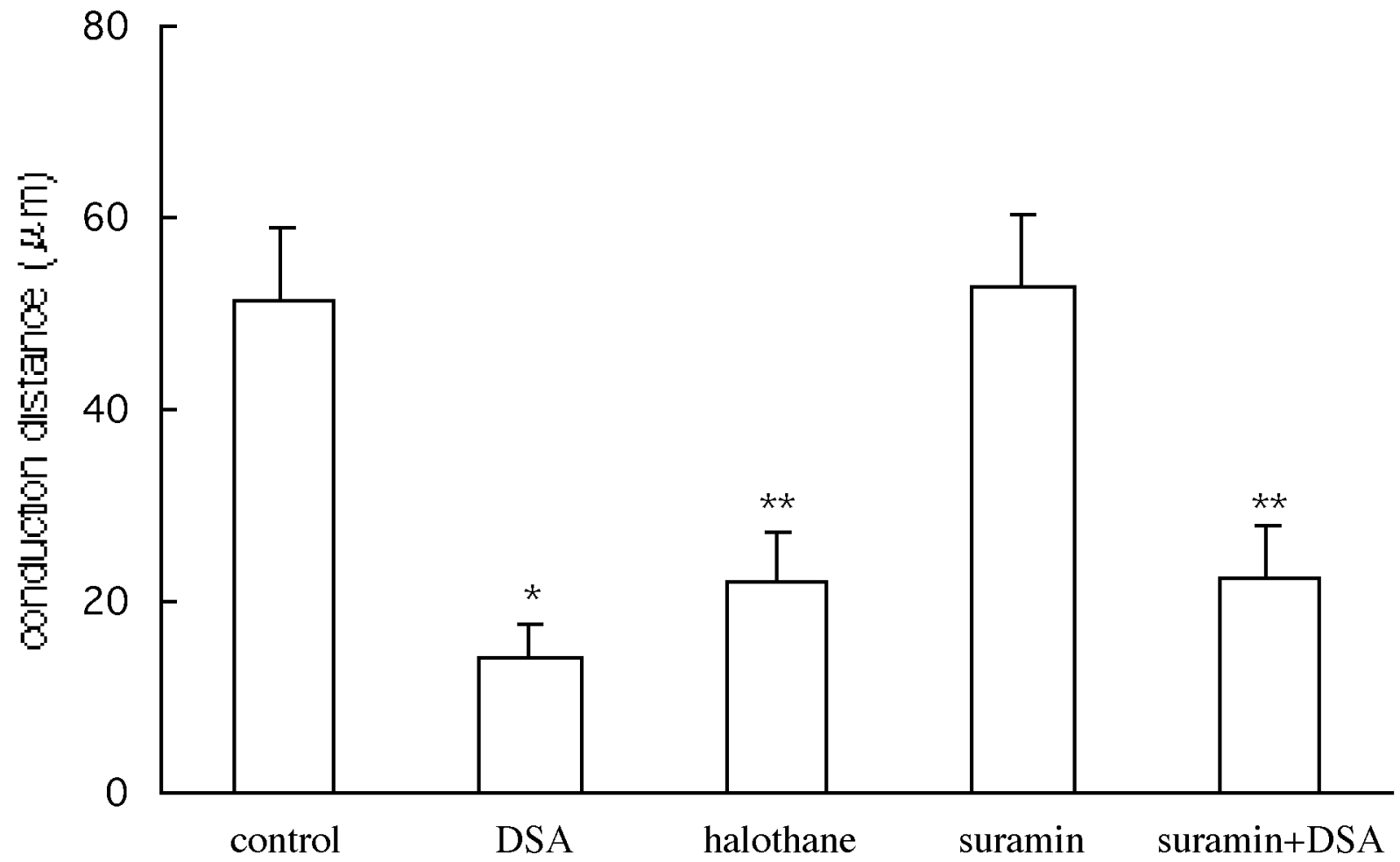

B

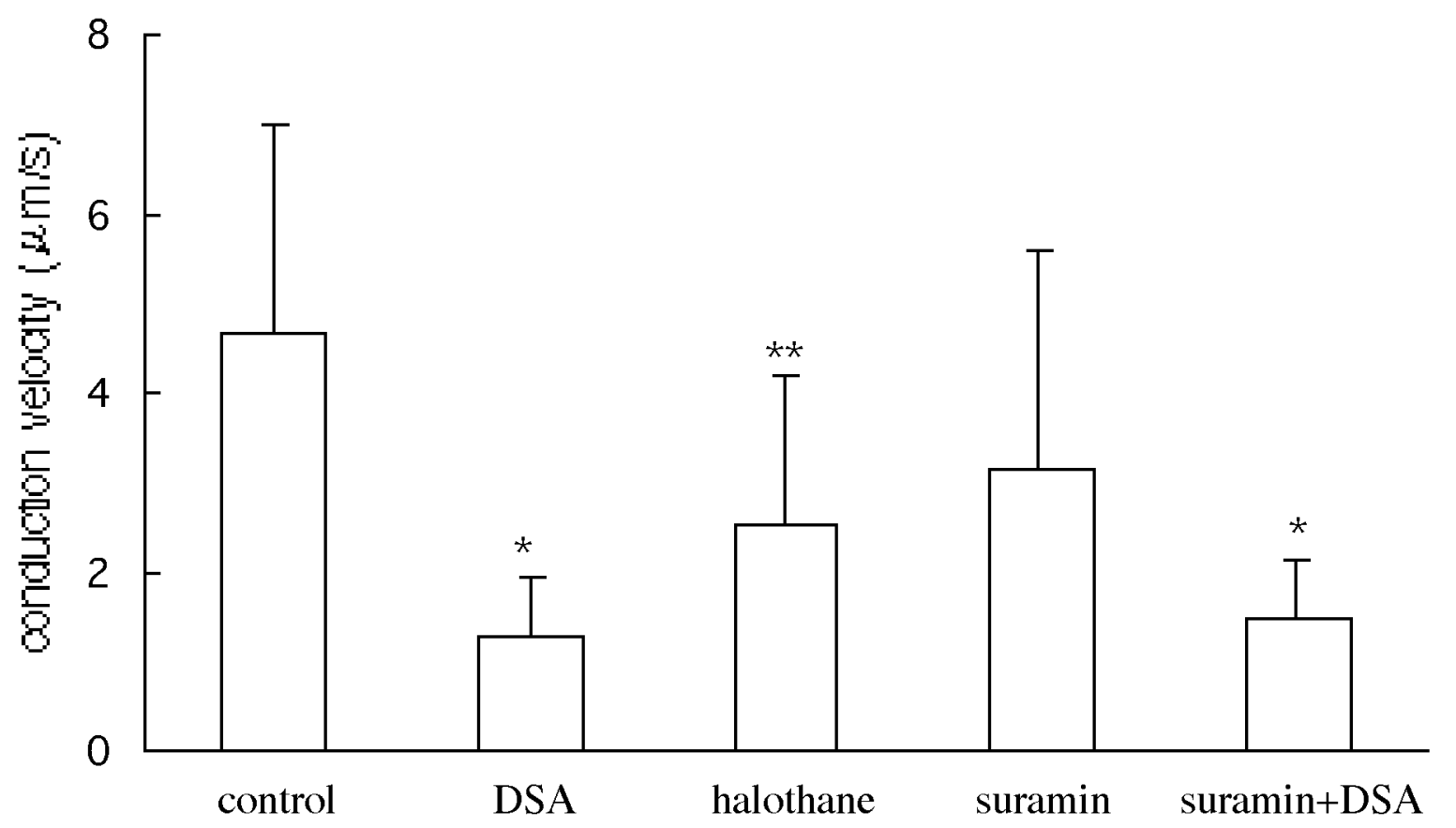



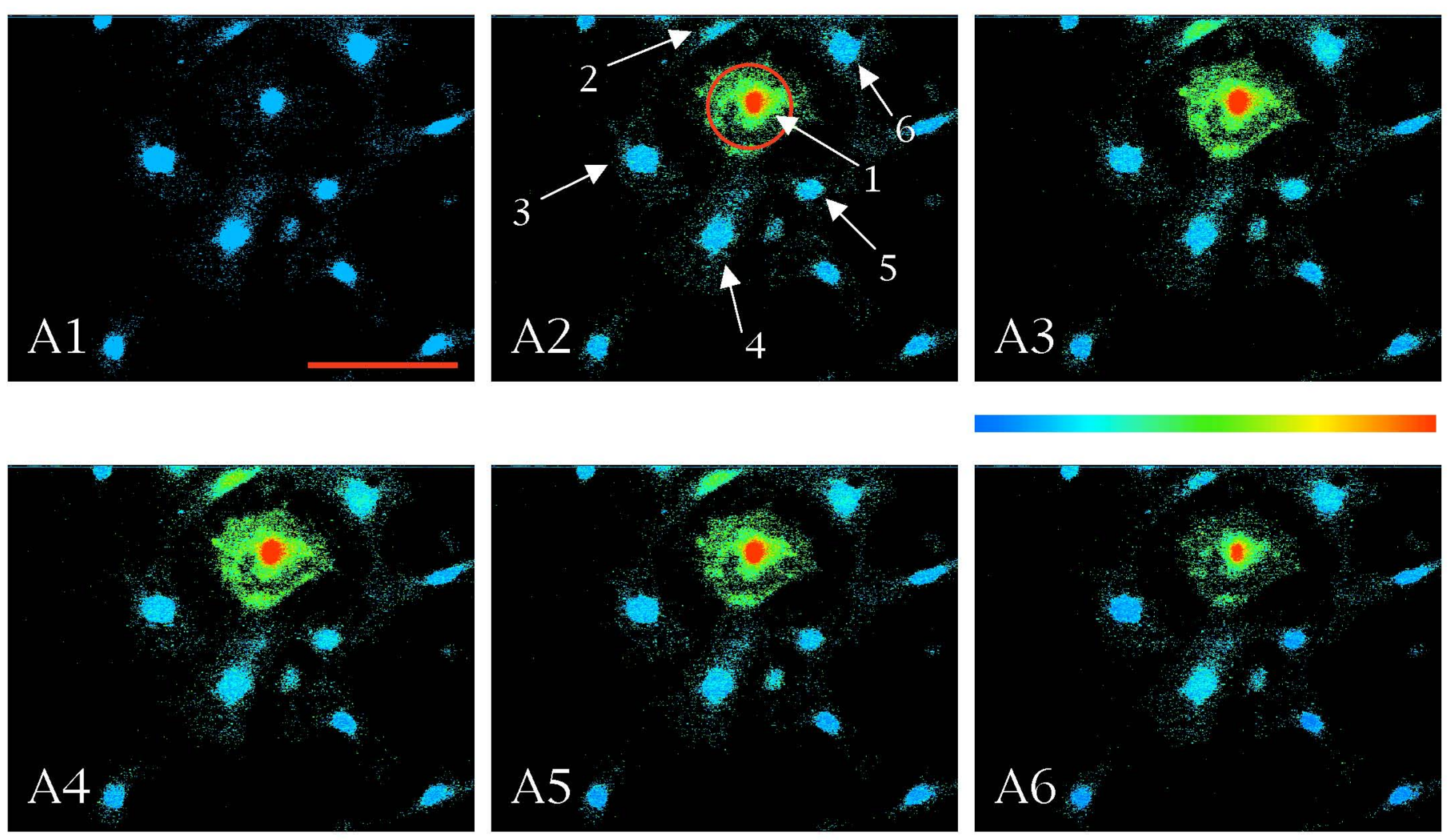

B

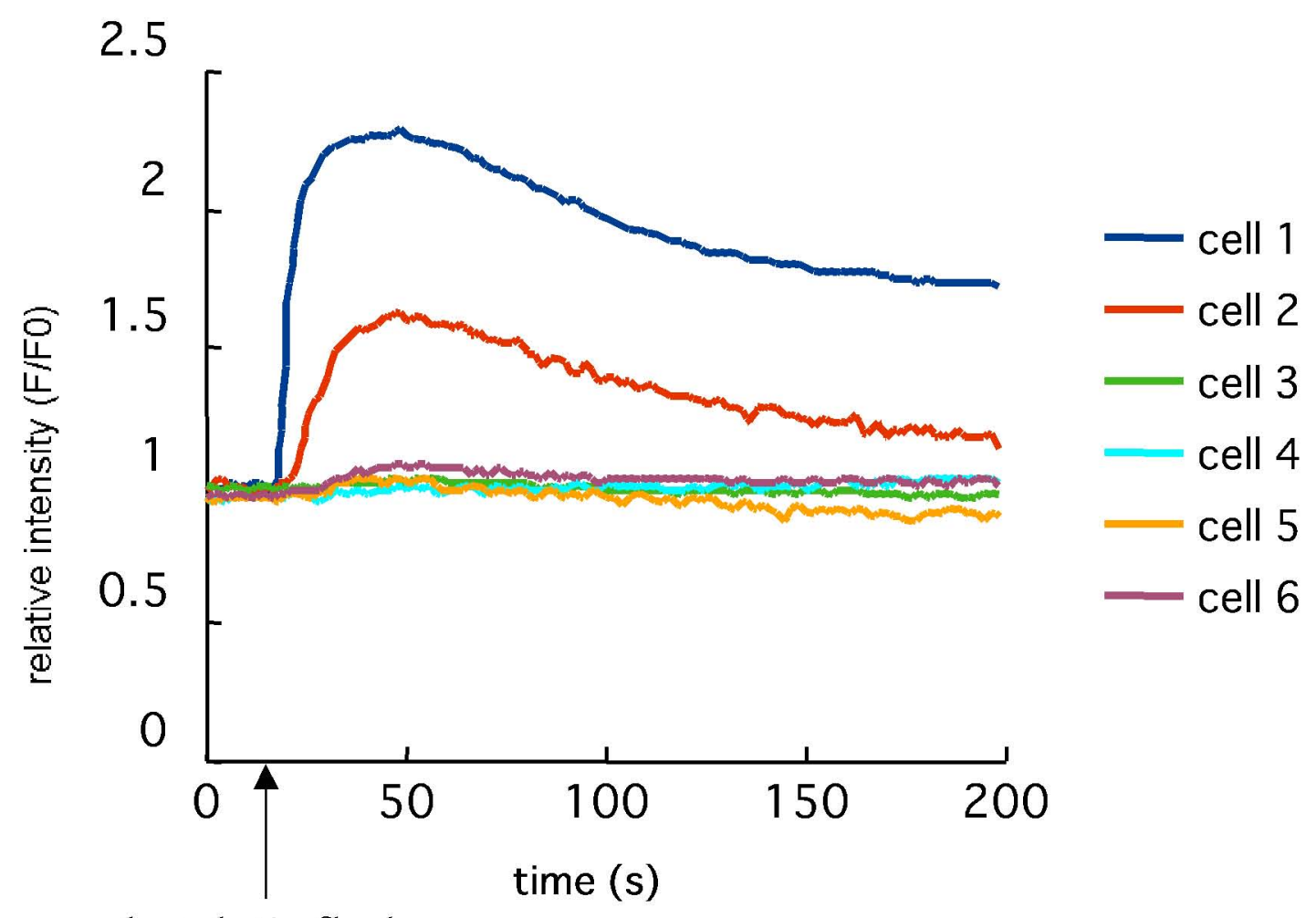

photolytic flash 